\title{
Classic galactosemia: dietary dilemmas
}

\author{
Annet M. Bosch
}

Received: 15 March 2010/Revised: 15 March 2010 / Accepted: 14 June 2010 /Published online: 13 July 2010

(C) The Author(s) 2010. This article is published with open access at Springerlink.com

\section{Introduction}

Classic galactosemia (McKusic 230400) is an inborn error of galactose metabolism caused by a deficiency of the enzyme galactose-1-phosphate uridyltransferase (GALT, EC 2..7.712), resulting in accumulation of the metabolites galactitol and galactose-1-phosphate. Patients ingesting galactose from breast milk or infant formula present in the first weeks of life with feeding difficulties, hepatocellular dysfunction, hypoglycemia, renal tubular dysfunction, cataract, and sepsis. Immediate removal of galactose from the diet results in a full recovery from this life-threatening neonatal crisis (Holton et al. 2001; Bosch 2006).

Mason and Turner (1935) were the first to report the successful use of a milk-free diet in an infant with galactosemia. In the $1950 \mathrm{~s}$, different strategies to feed infants a diet without galactose were discussed in the literature (Salt et al. 1955; Jones and Leak 1959). Nowadays, initiating the diet is much easier, as infant formulas with a very limited amount of galactose are widely available. Still, there are dilemmas in the treatment of galactosemia, and the dietary treatment varies widely around the world. The most troubling issue is that despite a continued galactose-restricted diet, and irrespective of a neonatal crisis, many patients suffer from long-term complications, such as reduced cognitive ability, language

Communicated by: Gerard T. Berry

Competing interest: None declared.

A. M. Bosch $(\bowtie)$

Department of Pediatrics (H7-270), Academic Medical Center, University of Amsterdam,

Meibergdreef 9,

1105 AZ Amsterdam, The Netherlands

e-mail: a.m.bosch@amc.uva.nl impairment, decreased bone mass, and hypergonadotrophic hypogonadism in women (Kaufman et al. 1981; Waggoner et al. 1990; Schweitzer et al. 1993; Panis et al. 2004; Potter et al. 2008; Schadewaldt et al. 2010).

\section{Infancy}

In the first weeks of life, the most important part of managing patients with classic galactosemia is removing all galactose from the diet as soon as the diagnosis is suspected, immediately after starting the diagnostic investigations and without awaiting results, in order to prevent further life-threatening complications. Whereas classic galactosemia is part of the newborn screening programs of many countries, most children will present with clinical symptoms, such as feeding problems, jaundice progressing to liver failure, and sepsis, before the screening results are available. Infants with classic galactosemia must be prescribed a galactose-free formula. In The Netherlands, the recommended treatment is soy milk; in some other countries, infant formula on the basis of casein hydrolysate and dextrine maltose as carbohydrate source, such as Nutramigen ${ }^{\circledR}$, is recommended. The safety of long-term use of soy milk has been much debated; however, there is no clinical evidence for harmful effects of this product (Merritt and Jenks 2004; Turck 2007). Both Nutramigen and soy formula still contain very small amounts of galactose, and recent studies demonstrated that completely eliminating galactose from the diet by prescribing an elemental formula $\left(\right.$ Neocate $\left.^{\circledR}\right)$ instead of Nutramigen ${ }^{\circledR}$ or soy formula caused a significantly faster decrease of the high erythrocyte Gal-1-P values that are found in infancy in these patients (Ficicioglu et al. 2005; Zlatunich and Packman 2008). As the time of diagnosis and 
the occurrence of the neonatal crisis do not seem to have a significant effect on long-term outcome, it remains to be elucidated whether this rapid decrease would positively affect outcome, and long-term studies need to be performed to clarify this before routinely putting these infants on this expensive and unpalatable formula (Schweitzer-Krantz 2003).

\section{Childhood}

With the introduction of solid foods, some galactose will inevitably be introduced into the diet, as many foods, such as fruit and vegetables, bread, legumes, and offal, contain trace amounts of galactose (Gross and Acosta 1991; Acosta and Gross 1995). Bound galactose is found in many vegetables as part of raffinose and stachyose. How much of this bound galactose can be broken down in the gut is not known. No significant contribution to the intake of galactose, or effect on biochemical parameters, has been demonstrated (Wiesmann et al. 1995).

There are major controversies concerning the daily allowance of galactose during long-term treatment. Many European metabolic centers recommend a very strict diet, also restricting galactose containing fruits and vegetables. Other centers, e.g., in the UK, Germany, The Netherlands, and the USA, are more liberal, advising only a lactose-free diet. There is limited knowledge of the tolerance for exogenous galactose in patients with classic galactosemia. A newborn infant with galactosemia ingesting $300 \mathrm{ml}$ of formula or breast milk per day in the first days of life, equivalent to $>7,000 \mathrm{mg}$ of galactose, will develop severe illness. As soon as the diagnosis is suspected, the galactose intake will be restricted as much as possible. Patients on a lactose-free diet with no restrictions of fruit and vegetables will have a daily intake of galactose $<30 \mathrm{mg}$ (Berry et al. 1993; Bosch et al. 2004a). On a diet enriched in fruit and vegetables, this intake increases to an average of $54 \mathrm{mg}$ of galactose per day (Berry et al. 1993). In one study, three adolescents ingested up to $600 \mathrm{mg}$ of galactose per day for 6 weeks without any effect on clinical or laboratory parameters (Bosch et al. 2004a). Of importance is the strong contrast between the exogenous intake of galactose in the lactose-restricted diet, with an average intake of $54 \mathrm{mg}$ of galactose per day with a diet enriched in galactose-containing fruit and vegetables and the endogenous production of galactose in adult patients, amounting to $1,000 \mathrm{mg}$ per day (Berry et al. 2004, Huidekoper et al. 2005). This fact is an argument not to restrict fruit and vegetables from the diet. Also, after the introduction of a less restricted diet in Australia, no increases in gal-1-p values were detected (Thompson et al. 2003). Furthermore, in the UK, where fruit and vegetables are not restricted from the diet, no new cataracts or liver diseases have been reported in the literature. It has been demonstrated that the endogenous production of galactose is not affected by the exogenous intake from the diet. (Huidekoper et al. 2005)

\section{Adulthood}

There is no insight into galactose tolerance of adults patients with classic galactosemia. Two remarkable patients have been reported in the literature. A 38-yearold adult woman and a 34-year-old man, both with classic galactosemia (Q188R homozygous), had both discontinued their diet at the age of 3 years (Lee et al. 2003; Panis et al. 2006). Her intake of galactose was $2,690 \mathrm{mg}$ per day, and his daily galactose intake was $9,000 \mathrm{mg}$. In both patients, there were no signs of cataract or liver disease, and red cell galactose-1-phosphate and urine galactitol were within the range of treated galactosemics. The female patient had started hormonal replacement therapy at 15 years of age because of primary amenorrhoea. Her neuropsychological assessment showed a verbal IQ of 88 and a performance IQ of 78; tests of attention, memory, and executive functions were below the tenth percentile for a normal population. The male patient had an unremarkable neurologic examination and a normal educational attainment. His in vivo oxidation of [1-13C] galactose was evaluated and found to be severely hampered and within the range for treated patients. These patients' outcomes seem no worse than in many patients with classic galactosemia treated with a strict diet. It is very well possible that the galactose tolerance of patients with classic galactosemia increases with age as a result of the age-related decrease of endogenous galactose production (Berry et al. 2004; Schadewaldt et al. 2004). It might also be possible that these patients have a greater capacity to dispose of galactose by pathways yet unknown. Alternatively, other factors, such as an aldose reductase deficiency as reported in the galactosemic mouse, may play a role (Ai et al. 2000; Segal 2004). In addition, it is not known whether red cell galactose-1-phosphate or urinary galactitol reflect the long-term toxicity of galactose in galactosemia. Longterm exposure to galactose could result in abnormal galactosylation of glycoproteins and glycolipids, and these patients might well have had an even better cognitive outcome if they had continued their diet.

\section{Future perspectives}

Based on the theory that exogenous galactose tolerance increases in adulthood, partly due to the relative decrease in 
endogenous production, relaxation of the galactoserestricted diet in adulthood might be considered (Berry et al. 2004; Schadewaldt et al. 2004). A slight relaxation, such as a lactose-restricted diet without limitations in intake in fruit and vegetables can very well be justified in the light of the available evidence and is the standard of care in many countries. Increasing the daily galactose intake from 27 to $54 \mathrm{mg}$ per day is a minor increase when considering the fact that an adult will have an endogenous production up to $1,000 \mathrm{mg}$ per day (Berry et al. 2004; Huidekoper et al. 2005). A further relaxation of the diet, however, will cause a major increase of daily galactose intake. As milk and milk-containing products such as yoghurt contain 2,400 and $1,800 \mathrm{mg}$ of galactose per $100 \mathrm{mg}$, respectively, the intake of even one glass of milk rapidly increases the daily intake to more than $4,800 \mathrm{mg}$ per day, more than four times the daily endogenous production. Therefore, full dietary relaxation should probably be strongly discouraged until the pathophysiology behind the long-term complications has been elucidated and it is clear whether or not this is related to galactose intake. Long-term studies, preferably after developing a more valid biochemical marker for galactose toxicity, evaluating the biochemical and clinical effects of exogenous galactose in adults as well as in children, are necessary before any further relaxation of the diet can be considered.

Even though a lifelong diet will affect the daily lives of the patients, a lactose-free diet without restriction of fruit and vegetables is a palatable and not very complicated diet. Studies have demonstrated that patients with classic galactosemia have a severely hampered quality of life (Bosch et al. 2004b). However, it has been demonstrated that this is the result of the late complications that are found in many patients and not a result of the diet (Bosch et al. 2009). As the late complications may result from continuous intoxication by galactose from endogenous production, dietary relaxation might well increase the long-term complications by rapidly increasing galactose load and thus affect patients' quality of life even more.

Open Access This article is distributed under the terms of the Creative Commons Attribution Noncommercial License which permits any noncommercial use, distribution, and reproduction in any medium, provided the original author(s) and source are credited.

\section{References}

Acosta PB, Gross KC (1995) Hidden sources of galactose in the environment. Eur J Pediatr 154(suppl 2):s87-s92

Ai Y, Zheng Z, O'Brien-Jenkins A, Bernard DJ et al (2000) A mouse model of galactose-induced cataracts. Hum Mol Genet 9 (12):1821-1827
Berry GT, Palmieri M, Gross KC et al (1993) The effect of fruit and vegetables on urinary galactitol excretion in galactose-1phosphate uridyltransferase deficiency. J Inherit Metab Dis 16:91-100

Berry GT, Moate PJ, Reynolds RA et al (2004) The rate of de novo galactose synthesis in patients with galactose-1-phosphate uridyltransferase deficiency. Mol Genet Metab 81:22-30

Bosch AM (2006) Classical galactosaemia revisited. J Inherit Metab Dis 29(4):516-525

Bosch AM, Bakker HD, Wenniger-Prick LJ, Wanders RJ, Wijburg FA (2004a) High tolerance for oral galactose in classical galactosaemia: dietary implications. Arch Dis Child 89 (11):1034-1036

Bosch AM, Grootenhuis MA, Bakker HD, Heijmans HS, Wijburg FA, Last BF (2004b) Living with classical galactosemia: health-related quality of life consequences. Pediatrics 113 (5):423-428

Bosch AM, Maurice-Stam H, Wijburg FA, Grootenhuis MA (2009) Remarkable differences: the course of life of young adults with galactosaemia and PKU. J Inherit Metab Dis 32(6):706712

Ficicioglu C, Hussa C, Yager C, Segal S (2005) Effect of galactose free formula on galactose-1-phosphate in two infants with classical galactosemia. J Inherit Metab Dis 28(2):163-168

Gross KC, Acosta PB (1991) Fruit and vegetables are a source of galactose: implications of planning the diets of patients with galactosemia. J Inherit Metab Dis 14:253-258

Holton JB, Walter JH, Tyfield LA (2001) Galactosemia. In: Scriver CR, Beaudet AL, Sly WS, Valle D, Childs B, Kinzler KW et al (eds) The metabolic and molecular basis of inherited disease, 8th edn. McGraw-Hill, New York, pp 1553-1583

Huidekoper HH, Bosch AM, van der Crabben SN, Sauerwein HP, Ackermans MT, Wijburg FA (2005) Short-term exogenous galactose supplementation does not influence rate of appearance of galactose in patients with classical galactosemia. Mol Genet Metab 84(3):265-272

Jones NL, Leak D (1959) The treatment of congenital galactosaemia. Arch Dis Child 34:307-311

Kaufman FR, Kogut MD, Donnell GN, Goebelsmann U, March C, Koch R (1981) Hypergonadotropic hypogonadism in female patients with galactosemia. N Engl J Med 304:994-998

Lee PJ, Lilburn M, Wendel U, Schadewaldt P (2003) A woman with untreated galactosaemia. Lancet 362(9382):446

Mason HH, Turner ME (1935) Chronic galactemia, report of case with studies on carbohydrates. Am J Dis Child 50(2):359-374

Merritt RJ, Jenks BH (2004) Safety of soy-based infant formulas containing isoflavones: the clinical evidence. J Nutr 134:1220s$1224 \mathrm{~s}$

Panis B, Forget PP, van Kroonenburgh MJ, Vermeer C, Menheere PP, Nieman FH, Rubio-Gozalbo ME (2004) Bone metabolism in galactosemia. Bone 35(4):982-987

Panis B, Bakker JA, Sels JP, Spaapen LJ, van Loon LJ, RubioGozalbo ME (2006) Untreated classical galactosemia patient with mild phenotype. Mol Genet Metab 89(3):277-279

Potter NL, Lazarus JA, Johnson JM, Steiner RD, Shriberg LD (2008) Correlates of language impairment in children with galactosaemia. J Inherit Metab Dis 31(4):524-532

Salt HB, Ross CAC, Gerrard JW (1955) Low-lactose milk for congenital galactosemia. Lancet 265(6875):1177-1178

Schadewaldt P, Amalanathan L, Hammen HW, Wendel U (2004) Age dependence of endogenous galactose formation in Q188R homozygous galactosemic patients. Mol Genet Metab 81:31-44

Schadewaldt P, Hoffmann B, Hammen HW, Kamp G, Schweitzer-Krantz S, Wendel U (2010) Longitudinal assessment of intellectual achievement in patients with classical galactosemia. Pediatrics 125 (2):374-381 
Schweitzer S, Shin Y, Jacobs C, Brodehl J (1993) Long-term outcome in 134 patients with galactosemia. Eur J Pediatr 152:36-43

Schweitzer-Krantz S (2003) Early diagnosis of inherited metabolic disorders towards improving outcome: the controversial issue of galactosaemia. Eur J Pediatr 162(Suppl 1):S50-S53

Segal S (2004) Another aspect of the galactosemic enigma. Letter to the editor. Mol Genet Metab 81:253-254

Thompson SM, Netting MJ, Jerath S, Wiley V (2003) Effect of a less restricted diet in galactosemia. J Inherit Metab Dis 26(suppl 2):214
Turck D (2007) Soy protein for infant feeding: what do we know? Curr Opin Clin Nutr Metab Care 10(3):360-365

Waggoner DD, Buist NRM, Donnell GN (1990) Long-term prognosis in galactosemia: Results of a survey of 350 cases. J Inherit Metab Dis 13:802-818

Wiesmann UN, Rose-Beutler B, Schluchter R (1995) Leguminosae in the diet: the raffinose-stachyose question. Eur J Pediatr 154(suppl 2):s93-s96

Zlatunich CO, Packman S (2008) Galactosaemia: early treatment with an elemental formula. Eur J Pediatr 167(5):595-596 